\title{
Cuba: la democratización pospuesta
}

\section{Lázaro de Jesús González*}

Perfiles Latinoamericanos, 25(50)

2017 | pp. 59-81

DOI: $10.18504 / \mathrm{pl} 2550-004-2017$

\section{Resumen}

Este ensayo presenta algunas de las principales carencias democráticas de la Cuba actual. Con un enfoque teórico-práctico, el autor pone a dialogar sus experiencias con los aportes conceptuales de destacados científicos sociales contemporáneos. Explica el funcionamiento partidocrático, burocratizado y postotalitario del "socialismo de Estado" cubano, y sus adversas consecuencias para la ciudadanía. Por último, analiza el desarrollo de las reformas en curso y, en ese contexto, expone los pilares fundamentales que debería incluir el proceso de democratización de la sociedad cubana.

\section{Abstract}

This essay presents some of the major Cuba's democratic shortcomings nowadays. With a theoretical and practical approach, the author establishes a dialogue between his experiences and the conceptual contributions of prominent contemporary social scientists. He explains, "particratic", bureaucratic and post-totalitarian performance of the Cuban's "state socialism", and its adverse consequences for citizenship. Finally, he analyzes the development of the ongoing reforms and, in this context, he exposes the fundamental pillars that the democratization of Cuban society should include.

Palabras clave: Cuba, democracia, ciudadanía, libertades, cultura, política, tolerancia. Keywords: Cuba, democracy, citizenship, freedoms, culture, politics, tolerance.

* Maestro en Sociología por la Universidad Iberoamericana de la Ciudad de México. En la actualidad cursa el Doctorado en Ciencia Social con especialidad en Sociología, en el Centro de Estudios Sociológicos de El Colegio de México | ljgalv@gmail.com 
La democracia inconclusa, haciéndose, no admite ni que esté "hecha" ni que esté siempre "por hacer", como una eterna promesa, que con razón lleva a descreer al final en ella.

NoRbert Bilbeny

- 0 os violentos sucesos que protagonizaron decenas de cubanos en las calles de la ciudad de Panamá el pasado 2015, me avergonzaron. Hirieron mi orgullo patrio. Aunque conozco de trifulcas y golpizas similares puertas adentro en la isla antillana, lamento la exportación de semejantes alardes de incivilidad hacia el espacio público internacional. Los representantes cubanos ${ }^{1}$ en el Foro de la Sociedad Civil, realizado en el contexto de la VII Cumbre de las Américas, solo dieron muestras de la precariedad del apellido que pretenden sostener. ¿Qué tiene de civil una sociedad que resuelve sus divergencias ideológicas por medio de la violencia (física o verbal)? Más bien parecen hombres y mujeres sumidos en el más genuino "estado de naturaleza" (Hobbes, 1982; Locke, 1990).

Eso de agarrarse a trompadas, gritos y empujones es denigrante. No existen excusas válidas para enlodar el patio ajeno con ataques de intolerancia. ${ }^{2} \mathrm{Si}$ un invitado no es capaz de confrontar sus ideas con las del rival en términos pacíficos, al menos debe tener la decencia de retirarse sin causar disturbios, hasta que aprenda el arte de disputar en condiciones de respeto mutuo. Lo curioso es que la delegación cubana oficial sabía con gran antelación que encontraría a opositores en dichas mesas de debate. Y pregunto: si no estaban dispuestos a polemizar, ¿a qué fueron? Al parecer, a dar fe internacional de su incultura deliberativa, criticada incluso por delegados oficialistas.

No solo Colombia requiere diálogos de paz. Y a la luz de estos hechos, se me antoja paradójico que justo Cuba sea el escenario de la negociaciones entre acérrimos enemigos, hasta hace poco enfrentados armas mediante. ¿Son más irreconciliables los conflictos entre cubanos? Sinceramente, no lo creo. A la necesidad de que Cuba asuma un proceso de democratización dedicaremos este ensayo.

1 Por cierto, la representación de la "sociedad civil oficial" cubana incluyó a varios diputados del Parlamento nacional, a la segunda jefa de la Unión de Jóvenes Comunistas y hasta un exministro, actual asesor del presidente. Todos actores políticos del máximo nivel. ¿Había que reforzar a los comisionados civiles? ¿No es suficiente la ya intensa politización de las organizaciones civiles oficiales, altamente subordinadas a los intereses partidistas y estatales?

2 Los actos de indisciplina tuvieron patéticos ecos en los foros previos al encuentro de jefes de Estado: al menos dos mesas de debate, "Gobernabilidad y democracia" y "Participación ciudadana", fueron arbitraria y premeditadamente boicoteadas por hordas enardecidas de delegados cubanos oficialistas. 


\section{Partidocracia contra pluralismo}

Me gustaría saber la opinión de Chantal Mouffe sobre semejante derroche de incivilidad desatado en el istmo panameño. Me encanta su noción de "pluralismo agonístico"; sin embargo, ;qué difícil llevarla a la práctica! Indomables pasiones humanas sabotean su concreción. En vistas de la imposibilidad de suprimir los conflictos inherentes a la política, Mouffe aboga por una ideal cultura de la tolerancia, que trascienda el mero discurso (se exprese en prácticas sociales) y asuma al "otro" como un "adversario legítimo" y no como un enemigo a destruir. En su original concepción, el adversario es "alguien cuyas ideas combatimos pero cuyo derecho a defender dichas ideas no ponemos en duda", porque compartimos con él la "adhesión a los principios ético-políticos de la democracia liberal: la libertad y la igualdad" (Mouffe, 2012: pp. 114115). Ideas convergentes con la conocida frase atribuida a Voltaire (y que en Cuba suena a herejía de las peores): "Estoy en desacuerdo con lo que dices, pero defenderé con mi vida tu derecho a decirlo". ${ }^{3}$

Mouffe contrasta dos tipos de antagonismo: 1) el antagonismo que tiene lugar entre enemigos (personas que no comparten una esfera simbólica común), y 2) el agonismo: manifestación civilizada del antagonismo, distinguida por establecer una relación entre adversarios. Los adversarios devienen "enemigos amistosos", porque comparten el mismo espacio simbólico, el cual, empero, quieren organizar de modos diferentes.

El problema de Cuba es que no hay cabida para adversarios de ningún tipo. Y no la hay porque tenemos serios déficits democráticos, en las dimensiones jurídica, institucional y cultural, por solo mencionar algunas. Aunque suene anacrónico, el régimen socialista vigente reproduce todavía muchos rasgos del obsoleto modelo soviético: fusión Estado-Partido, organización hipercentralizada de la sociedad, mecanismos de control social harto coercitivos e interpretación discrecional de las leyes, entre otros. Es un contexto donde "el Estado de derecho es sustituido por los amplísimos y arbitrarios derechos del Estado" (Chaguaceda \& González, 2013: p. 52), favorecido, en buena medida, por la debilidad de la esfera pública.

No existen espacios para partidos opositores ni organizaciones independientes del aparato estatal; la Constitución no los autoriza. ${ }^{4}$ En su monólogo

3 La autora de la frase es la biógrafa británica de Voltaire, Evelyn Beatrice Hall, quien escribía bajo el seudónimo "S.G. Tallentyre". Así quedó demostrado en el libro They Never Said It: A Book of Fake Quotes, Misquotes, and Misleading Attributions (Oxford University Press, 1989).

4 "En dos artículos constitucionales se establece que el derecho de asociación se verifica dentro del Estado: el 7 y el 53 . El primero señala que el Estado 'reconoce, protege y estimula a las organizaciones sociales y de masas', [...]. Pero al final del artículo se agrega que estas organizaciones 'cumplen directamente fun- 
comunista, el gobierno considera a todos los opositores como enemigos, mercenarios, contrarrevolucionarios, apátridas, espurios y un largo etcétera. Existen pruebas de que algunos han recibido financiamiento de gobiernos extranjeros; ${ }^{5}$ pero definitivamente no es el caso de todos. Además, a muchos no les queda otra vía de subsistencia más que el apoyo económico desde el exterior. No hay de otra, pues en Cuba prácticamente todo es propiedad del Estado; el sector privado es muy incipiente y está subordinado a la venia estatal. Entonces, si este poderoso Estado-Partido viste a la totalidad de los "divergentes" con el mismo saco de "mercenario", ¿entonces quién puede ejercer sus derechos políticos de manera legítima? Solo los afines al régimen comunista.

Ningún grupo con otra ideología puede crear una organización civil o política e inscribirla en el registro legal. Existen varias, pero condenadas a la sombra de la ilegitimidad obligatoria, con membresías escuálidas y escasa articulación entre sí:

En Cuba, el campo político parece reproducirse desde una lógica ajena a la tensión histórica entre reforma y revolución, advertida por clásicos del pensamiento socialista como Lenin, Rosa Luxemburgo o André Gorz. Todos los actores políticos se mueven entre distintos horizontes de expectativas reformistas y la tensión entre los mismos adopta la forma de una anulación mutua de la legitimidad, no de la interpelación o la confrontación pública de distintos proyectos de la nación, la sociedad o el Estado (Rojas, 2015: p. 155).

Como el espacio público en la práctica es propiedad estatal, las organizaciones opositoras solo pueden reunirse en ámbitos privados, casi siempre bajo el acoso de los órganos de inteligencia y a expensas de la violencia física y/o psicológica de la policía (Aguirre, 2002). Grupos y plataformas disidentes como las Damas de Blanco, la Unión Nacional Patriótica de Cuba, Estado de saTs, la Comisión Cubana de Derechos Humanos y Reconciliación Nacional, el Movimiento Cristiano de Liberación, el Frente Nacional de Resistencia Cívica, el Frente Antitotalitario, entre otros, han sufrido reiteradamente la intimidación, ofensas, golpes, arrestos y ultrajes por parte de las fuerzas represivas (Chaguaceda \& Geoffray, 2015); así como constantes campañas de descrédito público.

Una parte menor de la población más enajenada y vil participa con entusiasmo en los vergonzosos actos de repudio que agreden física y moralmente a

ciones estatales'. Por su parte, el artículo 53, luego de reconocer el 'derecho de reunión, manifestación y asociación', especifica que 'las organizaciones sociales y de masas disponen de todas las facilidades' para el ejercicio de ese derecho. Con lo cual el derecho de asociación, que es un derecho civil, se convierte en un derecho estatal' (Rojas, 1997: p. 253).

5 Véanse los cables del servicio diplomático estadounidense desclasificados por la organización Wikileaks,por ejemplo, https://wikileaks.org/plusd/cables/08HAVANA613_a.html 
los disidentes. Otro segmento de ciudadanos — la mayoría — se arrellana en la inercia y la contemplación: no atacan a los opositores, pero tampoco condenan el vandalismo y la represión oficial. Muchos tienen miedo de sufrir las represalias del Estado todopoderoso. $\mathrm{Y}$ es que generalmente no vas a la cárcel por criticar al gobierno, pero la etiqueta de disidente o "desviado" suele acarrearte innumerables conflictos. En un país donde es casi imposible no delinquir en la vida cotidiana (el mercado negro es la primera economía), dichos contratiempos no son nada desdeñables: pérdida del empleo estatal o de la licencia para el trabajo particular, limitación de la movilidad y la comunicación en el interior del país, invitación al exilio, registros y allanamientos (con frecuencia extrajudiciales) de la morada, encarcelamientos relámpagos o prolongados (en Cuba no existe hoy un tribunal de garantías constitucionales ni el recurso del habeas $\left.\operatorname{corpus}^{6}\right)$, entre otros recursos coactivos (Azor, 2014). Las estadísticas son reveladoras:

En términos de racionalización e institucionalización gubernamental, por lo tanto, la situación de Cuba, Irán y Nicaragua guarda bastante semejanza con los regímenes sultanísticos que pretendían sustituir. Esto no significa que las revoluciones no tuvieran consecuencias: las masas se beneficiaron posiblemente del derrocamiento de los dictadores. Pero debemos recordar también que los regímenes revolucionarios de Cuba e Irán han encarcelado, asesinado y llevado al exilio a más ciudadanos que el de Batista o el del sha. ${ }^{7}$ (Linz, 2009: p. 575).

En la ciudadanía prima el instinto de autopreservación: piensan que no vale la pena exponerse si no pueden amplificar sus pensamientos a toda la comunidad/nación, pues el Estado mantiene el monopolio absoluto de los medios de comunicación y un rígido control de los contenidos, mediante el Departamento Ideológico del Partido Comunista de Cuba (PCC). De ello puedo dar fe testimonial, pues durante los cinco años que ejercí el periodismo en tres medios impresos de tirada nacional, sufrí en carne propia la tiranía ideológica del partido, eficientemente perpetrada a través de sus cuadros directores de medios.

6 Existió un Tribunal de Garantías Constitucionales y Sociales entre 1940 y 1952, cuando el golpe de Estado de Fulgencio Batista lo abolió, no formalmente pero sí de facto. Después de 1959, los líderes de la Revolución cubana —ni siquiera Fidel Castro, abogado de profesión y admirador de la Constitución de 1940 - no mostraron interés por rescatar esta democrática instancia de control de la constitucionalidad, que fue finalmente desactivada en 1973 (García, 2004). Algo parecido sucedió con el habeas corpus, vigente todavía en la Ley No. 5 "De Procedimiento Penal" (Título Ix); pero en la práctica inoperante.

7 "Es interesante que mientras que a Castro y Jomeini se les permitió exiliarse después de su primer desafío a Batista y al sha (tras los incidentes del cuartel Moncada en 1953 y del levantamiento de 1963, respectivamente), ellos trataron más duramente a los partidarios de Batista y del sha cuando llegaron al poder en 1959 y 1979, también respectivamente" (Linz, 2009: p. 575).

L. de J. González | Cuba: la democratización pospuesta Perfiles Latinoamericanos, 25(50) | Flacso México | pp. 59-81 | DoI: 10.18504/pl2550-004-2017 
Similar control del partido único anula de modo muy eficaz la posible elección de disidentes para cargos públicos. Históricamente, el gobierno nacional ha acotado la emergencia de liderazgos contestatarios y autónomos en el ámbito comunitario, combinando hábilmente acoso policíaco, inciviles actos de repudio, cruzadas difamatorias y presiones sociales extendidas a través de los órganos de base del PCC y de las diferentes organizaciones de masas paraestatales. A tales tácticas, han sumado en fechas recientes otras no menos reprensibles, como la modificación de las circunscripciones electorales locales ${ }^{8}$ (conocida en inglés como gerrymandering), las ilegales campañas internas de descalificación de opositores candidatos a cargos públicos, ${ }^{9}$ y los ya mencionados boicoteos de foros internacionales donde participen representantes de la oposición interna. En Cuba la desregulación de la política no tiene fronteras y es reconocida, incluso, por investigadores defensores del sistema:

La imprecisión en los límites que se ha dado en el sistema político respecto a otros sistemas, su concentración de poderes y su carácter irrestrictamente dominante en el marco de la sociedad de transición, propende a favorecer un régimen en el cual los distintos sistemas —el jurídico, el económico, el cultural, etcétera— quedan subordinados con fuerza al sistema político y afectados en su autonomía relativa. [...] Otro problema se refiere a los límites entre el sistema político y la población. En este caso, el régimen se expresa en la invasión de los espacios privados —efecto de la excesiva politización de la vida cotidiana—o en la desmedida regulación del comportamiento social —efecto de la hipertrofia del Estado y de su burocratización. (Valdés, 2009: p. 85).

Cabe precisar que con la citada dominación del sistema político, Juan Valdés Paz se refiere explícitamente al PCC "suplantando a las demás organizaciones políticas y de masas —en su orientación o representación—, o a las

8 A finales de 2012, la delegada municipal Sirley Ávila León, una campesina de la empobrecida zona oriental del país, ante la desatención gubernamental de su reclamo en contra del cierre de escuelas rurales en la circunscripción, acudió a la prensa independiente para denunciar lo sucedido. De inmediato comenzó a recibir el acoso de los inspectores agrarios y su electorado fue escindido a partir de una operación de gerrymandering, que rediseńó ad hoc su circuito local.

9 En las elecciones para delegados a las asambleas municipales celebradas en abril de 2015, por primera vez en la historia postrevolucionaria contendieron dos candidatos disidentes, propuestos por sus vecinos en La Habana. En los dos casos, las Comisiones de Candidatura manipularon arbitrariamente las autobiografías y las llenaron de dicterios, práctica prohibida por ley. Aunque estos contendientes no resultaron electos, fue muy sintomático que ambos ganaran alrededor de doscientos votos (189 y 233) de un millar de votos posibles en cada caso. Inclusive, uno de ellos quedó en segundo lugar en su demarcación. A ojos de observadores internacionales estos datos pudieran sonar irrisorios; pero en Cuba una golondrina así puede avizorar un verano más democrático. 
organizaciones estatales, particularmente a las Asambleas del Poder Popular y el Gobierno, en los distintos niveles" (2009: p. 86). Por añadidura, desde los primeros años de la Revolución cubana, siempre el líder del PCC ha ocupado la presidencia conjunta del Consejo de Estado (órgano legislativo) y del Consejo de Ministros (entidad ejecutiva), junto a la máxima jefatura de las Fuerzas Armadas. En medio siglo solo hemos tenido dos mandatarios casi vitalicios: Fidel y Raúl Castro. Aunque este último, tras promover en 2012 el límite de todos los mandatos a dos periodos de cinco años, anunció al año siguiente su definitiva salida de la presidencia del país (que no del PCC) para 2018, cuando cumplirá ¡ 87 años! En síntesis, siempre una persona ha concentrado los poderes legislativo, ejecutivo y militar.

El diseño institucional de asamblea unicameral —ni presidencialista ni parlamentario - consagra, incluso desde la Constitución, el principio del "centralismo democrático". Este método político "inhabilita la existencia de controles cruzados, interinstitucionales, aunque se reconoce la independencia de la función judicial"; ${ }^{10}$ y "no permite la existencia de minorías parlamentarias y apenas se consagran garantías contramayoritarias (que impidan u obstaculicen a una mayoría legislar sobre temas especialmente protegidos)" (Guanche, 2013: p. 41).

A nivel municipal y provincial — donde un mismo órgano asambleario concentra las funciones estatales y gubernamentales-, en la práctica, por encima de los (electos) presidentes de las Asambleas Provinciales han gobernado los (designados) secretarios del partido, bajo métodos de conducción más directivos que normativos. ${ }^{11}$ Para autores residentes en la isla caribeña, esta usurpación del Estado por el partido, que se abroga un mandato imperativo en todas las instancias, aniquila cualquier posibilidad de establecer un verdadero poder popular:

10 La citada "independencia del poder judicial” también es puramente nominal. En Cuba, la función judicial está a cargo del Tribunal Supremo Popular, el cual, al no calificar como un "Órgano Superior del Poder Popular” (Capítulo x de la Constitución de la República [1976]), no tiene la exclusividad y unidad de la jurisdicción. "Los tribunales constituyen un sistema de órganos estatales, estructurado con independencia funcional de cualquier otro y subordinado jerárquicamente a la Asamblea Nacional del Poder Popular y al Consejo de Estado" (artículo 121 de la Constitución). De tal forma, "el Consejo de Estado puede suspender las decisiones del Consejo de Ministros y de las asambleas y órganos locales del Poder Popular, cuando no se ajusten a la Constitución o las Leyes. También imparte instrucciones a los tribunales y a las fiscalías, lo que convierte al poder judicial totalmente dependiente de un órgano político" (Diversent, 2014: p. 1). Asimismo, comprobamos que la Constitución, en su inciso ch) dispone que es atribución del Consejo de Estado "dar a las leyes vigentes, en caso necesario, una interpretación general y obligatoria” (artículo 90).

11 "En el caso de la dirección intergrupal, esta tendencia a una conducción partidaria directiva, basada en una nomenclatura de cuadros, se ha visto reforzada por la violación de sus propios mecanismos de selección y elección mediante prácticas de cooptación y designaciones” (Valdés, 2009: p. 88). 
Dentro del canon vigente (el supuesto de que el partido dirige al Estado), por sensatos, acertados, consensuados, justos y comprensivos que puedan ser los órganos de dirección, no pueden generar otra cosa que partidocracia (es decir autoritarismo partidario). Cuando es el partido el que decide, decide una elite. Que sean los mejores o no lo sean —incluso desde una definición programática — es un dato coyuntural, porque pueden dejar de serlo en otra generación, y creer que esta relación puede expresar una estructura democrática es un desacierto (la historia lo mostró ya). Se puede contar con un "rey bueno" o un "rey malo", pero esa diferencia no cambia el sentido de la monarquía. (Alonso, 2015).

Esta reprivatización del poder político por parte de la maquinaria burocrática partidista, que usurpa los espacios de democracia participativa y se aleja del control directo de las bases, nada tiene que ver con la concepción original del socialismo. ${ }^{12}$ Más bien tiende a: 1) desarrollar la estructura institucional del Estado burgués (en detrimento de los esquemas populares de autoorganización: consejos, comunas, sindicatos), 2) anular los procesos de socialización política de la sociedad en todos sus niveles, y 3) establecer la hegemonía de una nueva clase dominante: "una burocracia cada vez más amplia y despótica en sus relaciones con los trabajadores, y que en el curso de su consolidación y desarrollo comienza a autorreclutarse [...] y a mantener relaciones de producción/ apropiación de tipo explotativo" (Quijano, 2014: pp. 580-581). Este destacado pensador latinoamericano insiste en la necesidad de quebrar la ideología mítica y la práctica de los "socialismos reales" que preconizan a ultranza el sistema de partido único hegemónico.

Toda la experiencia histórica del movimiento triunfante o derrotado de los explotados señala que no es cierto, de manera alguna, que un solo partido sea el depositario de toda la conciencia revolucionaria de las masas de la clase, de toda su capacidad de permanente dominio teórico y práctico de la realidad histórica. $\mathrm{Y}$ en esta perspectiva, solamente el debate abierto, permanente y libre en las bases organizadas de la clase, y en consecuencia la presencia de varias organizaciones y tendencias políticas, puede realmente garantizar el desarrollo de la conciencia de la clase, y de ese modo mantener y desarrollar la relación democrática entre sus organismos y niveles de organización, en la lucha por el poder y en el ejercicio del mismo. (Quijano, 2014: p. 583).

12 "El monolitismo partidario como la idea de partido único, como canales del movimiento político de la clase, implican la idea del monolitismo de la clase. Y tal idea es extrańa a la historia y a la teoría materialista de la historia” (Quijano, 2014: p. 586). 


\section{Estado postotalitario-benefactor: el "ogro filantrópico"}

Así las cosas, tenemos en Cuba un sistema constitucionalmente partidocrático, que de facto coarta las libertades de organización, reunión y manifestación, de prensa y expresión, de elegibilidad e investigación. Libertades todas reconocidas por la Organización de las Naciones Unidas desde 1948 en su Declaración Universal de los Derechos Humanos ${ }^{13}$ y por la Carta Democrática Interamericana de la Organización de Estados Americanos. Semejantes privaciones pudieran englobarse bajo un nombre: autoritarismo con pespuntes totalitarios, si se quiere ser indulgente.

Sin embargo, en la notoria tipificación de Juan Linz (2009) de los regímenes no democráticos, el régimen político cubano ni siquiera clasificaría como autoritarismo; debido fundamentalmente a la ausencia de un legítimo pluralismo político, aunque sea formal, acotado, de semioposición o pseudooposición. Si bien, sería un error teórico y político catalogarlo de totalitarismo, como sí lo fueron el estalinismo y el fascismo, o parece ser la actual Corea del Norte.

De modo que el esquema democrático de la Revolución es, más bien, una combinatoria de mecanismos participativos, corporativos y representativos. Esta triple condición de la soberanía interna impide que, en la práctica, se totalicen absolutamente la sociedad y el Estado. Pero sólo dentro del engranaje institucional de esos mecanismos se dan las relaciones básicas entre el Estado y la Nación, entre la sociedad civil y la sociedad política, entre el gobierno y el pueblo. Es por eso que el régimen cubano, aunque no pueda ser definido como totalitario, demuestra cierta tendencia retórica y organizativa a la totalización de lo nacional y lo estatal, de lo cívico y lo político. El documento primario para leer dicha tendencia es la Constitución de la República de Cuba de 1976. (Rojas, 1997: p. 251).

De acuerdo con Linz (2009), la Cuba actual estaría viviendo un etapa postotalitaria, caracterizada entre otros rasgos por: 1) incipiente pluralismo social $^{14}$ y político (Rojas, 2015); 2) embrionaria apertura a formas económicas

13 Para una crítica de las violaciones o cumplimientos a medias patentes en el caso cubano, resultan de particular interés los artículos del 18 al 21.

14 "La pluralización civil de la sociedad cubana es uno de los efectos más visibles del avance hacia el capitalismo de Estado. En Cuba hay asociaciones raciales, sexuales y genéricas oficiales y alternativas, con diferentes grados de interlocución con las organizaciones del Estado, que presionan a favor de la igualdad étnica, sexual y de género en la isla. [...] El debate que esas comunidades sostienen con instituciones como el Centro Nacional de Educación Sexual, dirigido por Mariela Castro, diputada de la Asamblea Nacional del Poder Popular, o asociaciones más autónomas como la Cofradía de la Negritud y Color Cubano, da cuenta de un repertorio de sociabilidad e imaginación que desborda la institucionalidad estatal" (Rojas, 2015: pp. 148-149).

L. de J. González | Cuba: la democratización pospuesta Perfiles Latinoamericanos, 25(50) | FLACso México | pp. 59-81 | DoI: 10.18504/pl2550-004-2017 
no estatales (liberalización económica), aún bajo el férreo control estatal de sus condiciones de existencia; 3) oposición interna reducida (comparativamente hablando), fragmentada, marginada, sin base social —el gobierno a duras penas tolera cierta oposición "leal", moderadamente crítica y restringida al ámbito intelectual- (Chaguaceda \& Geoffrey, 2015); 4) partido único debilitado en cuanto a membresía y credibilidad, desgaste del liderazgo carismático, ideología monolítica en decadencia, poca fe en la utopía, tránsito al consenso pragmático, y 5) movilizaciones reactivas y rutinarias, crisis profunda de las organizaciones de masas.

[En Cuba] La emigración masiva (un 12 por ciento de la población, mayoritariamente a Estados Unidos y a Espańa) limitó la escala de la represión, aunque un reciente análisis muestra la dimensión del terror de Estado y su similitud con el modelo de represión soviético, incluyendo el duro castigo a los revolucionarios disidentes (Fonntaine, 1997). No se hizo prácticamente ningún intento académico para situar este sistema dentro de una perspectiva comparada. La hostilidad ante el concepto de totalitarismo descartaba su uso, a pesar que desde mi punto de vista estaban presentes los rasgos básicos. Considero que el indiscutible atractivo carismático de Castro y sus vínculos con la tradición latinoamericana del caudillismo no son obstáculos para caracterizar la institucionalización del régimen y sus políticas como totalitarias. La cuestión es hasta qué punto el carisma y el atractivo nacionalista son todavía la base de lo que podríamos denominar un régimen postotalitario. (Linz, 2009: p. 295).

En contraste, un intelectual criollo alternativo, Lenier González, cree que "resulta reduccionista y falso, adjudicar a 'la vocación totalitaria del Gobierno cubano' la causa primera y última que justifica un diseño singular ${ }^{15}$ de la participación social" (Torres et al., 2015: p. 2), por ejemplo. Por tanto, propone considerar "otros elementos de vital importancia que explican el porqué de las cosas", y que denomina "mediaciones históricas". Entre ellas, este joven católico enfatiza en dos eventos medulares: 1) la "guerra civil" o "lucha contra bandidos" (según desde donde se mire) acaecida entre 1960 y 1965, y 2) la institucionalización del rígido modelo sociopolítico soviético. Sobre la primera afirma que para la contención de los sectores opositores, "el joven Gobierno revolucionario restringió muchas libertades individuales y espacios políticos heredados de la Segunda República, con el propósito de abortar la posibilidad de que esos gru-

15 Siguiendo las propias palabras del autor, "singular" me resulta un gran eufemismo para disfrazar un "diseño de la participación social" en extremo vertical, meramente movilizativo, rutinario, reactivo y disfuncional. 
pos pudiesen organizarse, influir socialmente y tener acceso al poder" (Torres et al., 2015: p. 2). Respecto a la segunda mediación, argumenta que la Constitución de 1976 encumbra al PCC "en la cúspide del poder insular, consagra la nación en la ideología marxista-leninista, y acopla bajo su liderazgo a todas las organizaciones políticas y de masas, convertidas, en la práctica, en sus correas de transmisión" (Torres et al., 2015: p. 2).

El vicecoordinador general del proyecto "Cuba Posible" —una "Plataforma de Análisis y Diálogo" asociada a la mencionada oposición "leal”- insiste en agregar otro par de condicionantes a la disquisición sobre las carencias democráticas en Cuba, tales como: "el constante componente de agresividad por parte de Estados Unidos, que siempre apostó por el derrocamiento del Gobierno cubano", por un lado, y, por el otro, "el anhelo de un Estado fuerte, acompañado de un centralismo revolucionario que permitiera un control real de la política republicana". A su juicio, el primero "llevó a la construcción de un modelo de resistencia que impactó de forma severa la autonomía de lo social", y el segundo exigió "cuotas de lealtad severas por parte del entramado social" (Torres et al., 2015: p. 2).

Si bien concuerdo con Lenier González en la necesidad de huirle a los reduccionismos y sopesar integralmente la influencia de esos y otros factores (no pocas veces soslayados), sostengo que, inclusive bajo tales circunstancias (o en respuesta a ellas), el gobierno cubano pudo y debió fomentar durante las últimas cinco décadas unas prácticas, culturas y arquitectura institucional genuinamente democráticas; en suma, un entorno social más fuerte ante las adversidades y con mayor legitimidad internacional. A mi modo de ver, la democracia es perfectamente capaz de enfrentar con eficacia las mediaciones aducidas por González. A contrapelo de quienes achacan a la democracia una fragmentación y debilitamiento de la soberanía, converjo con Norbert Bilbeny cuando asevera que "Todas las enfermedades de la democracia pueden curarse con más democracia" (Bilbeny, 1999: p. 51).

De plano discrepo de las apelaciones a este tipo de realismo político y la justificación "contextual" de los excesos postotalitarios. Deviene cuando menos una ingenuidad exonerar al gobierno y los actores en el poder político de la responsabilidad "primera y última" del "diseño singular de la participación social” y el funcionamiento autocrático de la sociedad. Resulta una visión demasiado pasiva, condescendiente y orgánica respecto a los sujetos que toman las decisiones políticas, presentados por González casi como "víctimas" de las mediaciones. La reacción autoritaria ante la hostilidad exógena e interna, la importación poco matizada de un modelo totalitario, la estrangulación del pluralismo social, etc., no dependen principalmente de terceros, sino sobre todo de la clase política en el poder, los gobernantes, quienes traducen "lo político" 
en determinadas normas, estructuras, tramas y dinámicas sociales. Decir lo contrario significa el homicidio sociológico de un agente por derecho propio protagonista de la Historia. ${ }^{16}$

De tal modo, en mi criterio, tenemos un "socialismo de Estado" postotalitario y de bienestar. Como bien resume Rafael Rojas (1997: p. 255): "El Leviatán cubano, como ningún otro Estado benefactor, podría acogerse a la célebre definición de Octavio Paz: es un "ogro filantrópico". Grandes y valiosas garantías materiales (salud, educación y seguridad social ${ }^{17}$ ) — cuyos inobjetables méritos muchos opositores desconocen o tergiversan-, menoscabadas empero por serias carencias democráticas que partidarios del oficialismo, a su vez, ignoran, minimizan o justifican con disímiles sofismas, como el de "plaza sitiada". Por cierto, aplaudo el acercamiento diplomático entre los gobiernos de Cuba y Estados Unidos, pero celebraría aún más un incremento equitativo en los intercambios entre los pueblos de ambos países. Mucho aprenderíamos unos de otros. La tensa relación entre ideales prístinos como libertad, igualdad y justicia nos reserva todavía preciadas enseñanzas prácticas. ${ }^{18}$

\section{Apuesta por la ciudadanía}

Ahora bien, no entiendo cómo, debido a discrepancias ideológicas, ciudadanos cubanos llegan al extremo de agredirse física y verbalmente, con odio e insidia, en la misma ciudad en la que apenas unas horas después, Raúl Castro y Barack Obama intercambian apretones de manos, conversan de forma amigable y ordenan el restablecimiento de las relaciones bilaterales. Un suceso histórico, inimaginable meses antes. ¿Acaso son más solventes las diferencias de la sociedad política que las de la sociedad civil? ¿Es tan difícil sentarse entre adversarios civilizados a negociar ciertas reglas de coexistencia, respetuosas del

16 Pareciera que Lenier González invirtiera la célebre frase de Karl Marx: "Los hombres moldean su propia historia, pero no lo hacen libremente, influidos por condiciones que ellos han elegido, sino bajo las circunstancias con que se tropiezan inexorablemente, que están ahí, transmitidas por el pasado” (2004: p. 155). En ella el genio alemán reconoce la enorme trascendencia del contexto; pero asume que, atravesados por esas condicionantes, los actores son dueńos de sus actos y con sus decisiones construyen la realidad.

17 Conquistas cada vez más depauperadas, aunque todavía muy superiores a los estándares de América Latina y del resto del Tercer Mundo.

18 "La libertad es el principal valor moral de la democracia" y "la virtud de la libertad es la tolerancia" afirma Norbert Bilbeny (1999: p. 42), que en todo caso — acotaría yo — es un acto de justicia respecto a la dignidad del otro. Significa vivir sin ser discriminado ni discriminar, aceptar al otro y sus diferencias, integrarlo a partir de un esfuerzo intercultural, y no solo soportarlo o reconocerlo. 
disenso, incluyentes, justas para todos y que impliquen el reconocimiento del "otro" en vez de su anulación?

Por supuesto, las decisiones políticas dependen de un puñado de hombres; mientras que la sociedad civil (aunque las autoridades cubanas se nieguen a reconocerlo) es el escenario natural de un pluralismo infinito: millones de ideas, valores, habitus, representaciones y expectativas, más difíciles de conciliar. Ojalá las culturas políticas pudieran transformarse "de un plumazo diplomático". Me temo que medio siglo de intolerancia, aislamiento, monolitos ideológicos y soliloquios políticos han hecho mucho daño a mis familiares, vecinos, amigos, conocidos y paisanos en general. No obstante, quiero creer que es un daño reversible y que el sombrero de la democracia "encontrará cabeza" cuando por fin llegue a Cuba. Me constan los asombrosos cambios de mentalidad que produce la emigración (vivir para creer), o el simple contacto cotidiano con Internet (informarse para juzgar), aun sin salir de la Isla. Pero, por experiencia propia, apelo sobre todo al intercambio personal (socializar para crecer) y al mutuo entendimiento. ${ }^{19}$ Por eso, me gustaría ver a muchos más cubanos viajando por todo el orbe y, al mismo tiempo, a medio mundo visitando a Cuba (incluidos los estadounidenses, cuyo gobierno en la actualidad se los prohíbe).

Mi apuesta es, en definitiva, por un despertar de la ciudadanía democrática: una transmutación cultural que dé cabida no a una única idea normativa del bien común, a disposición del monopolio estatal de la violencia (u otro); sino a un sinfín de concepciones específicas y diferentes de la "vida buena", contradictorias inclusive, pero capaces de cohabitar bajo un mismo cielo democrático. Los cubanos no somos intolerantes o inflexibles por naturaleza. Prueba de ello es el nuevo ciclo político abierto entre el propio gobierno postotalitario y su vecino-antípoda.

Si bien reconozco la intención provocadora del esloveno Slavoj Žižek, explicitada en su libro En defensa de la intolerancia (2010), en el caso particular de Cuba no creo necesario ningún ardid psicoanalítico que incite a la pasión política y alimente aún más la discordia. Eso queda en todo caso para las "adultas" democracias liberales europeas, desgastadas por el paso del tiempo y sus propias rémoras. Los cubanos, por el contrario, debemos aún empezar a gatear hacia otra democracia: una particularmente filtrada por nuestra experiencia contextual e histórica, original pero reconocible en valores y prácticas universales, tales como: inclusión, responsabilidad, participación, civilidad, persuasión, deliberación, control, fiscalización, etcétera. Una dosis alta de tolerancia

19 La preocupación central de la política es el mundo de las "cosas" creadas por los hombres mediante el mutuo entendimiento; mundo que los condiciona y media entre ellos: los reúne y a la vez los separa (Arendt, 1997). 
resultaría un buen "andador" sobre el que impulsarnos en la errante travesía hacia la democratización.

Pero la tolerancia no implica de ninguna manera la pasividad ante los fanáticos que desean destruirla, desobedeciendo las reglas del juego democrático. La historia ya nos ha mostrado las graves consecuencias (los totalitarismos) que puede generar la tolerancia desmedida e incauta. La libertad no puede existir sin la tolerancia y esta, a su vez, sin la intolerancia a los intolerantes. No es un galimatías: "la tolerancia tiene un límite: no tolerar a quienes quieren acabar con ella. Ser 'anti-intolerantes'. Eso no representa ninguna contradicción. [...] Por congruencia consigo misma, la tolerancia no puede transigir con los intransigentes que la amenazan" (Bilbeny, 1999: p. 43). Dicha "anti-intolerancia" es la que nos ha faltado en Cuba, para evitar los desmanes totalitarios.

En parte, tal carencia se la debemos a una interpretación empobrecida y maniquea de la noción de ciudadanía y los derechos/deberes que implica. Escudado en la descalificación de los "derechos burgueses", ${ }^{20}$ el constitucionalismo socialista impugnó el concepto de ciudadano, y en su lugar implantó el de proletariado, cuya emancipación —en teoría— inspiraría la redención del resto de la sociedad. De hecho, no encontramos "en el cuerpo del socialismo 'marxista-leninista' un término que cumpla el papel que juega el de ciudadano en la trama del pensamiento democrático liberal. Los derechos ciudadanos son la clave de la relación democrática del ciudadano con el Estado" (Fernández \& Guanche, 2010: p. 6). Sin ellos los gobernados quedan reducidos a meros súbditos, clientes, usuarios o zombis harto manipulables que, como en Cuba, se prestan al juego sucio del Estado: actos de repudio, golpizas a opositores, pomposos desfiles de masas vacíos de contenido ciudadano, etcétera,

Las consecuencias respecto a la ciudadanía de la prevalencia de los derechos sociales sobre los individuales son conocidas: configura un patrón asistencialista de participación, crea un ciudadano pasivo a la espera de la provisión pública de bienes y servicios. Sin embargo, la cualidad del sistema democrático no está en aquello que se otorga, sino en aquello que se forma: no en lo que se entrega en forma de bienes y servicios sociales por parte del Estado, sino en la calidad de ciudadano que puede ser ejercida dentro de ese diseño político. (Fernández \& Guanche, 2010: p. 6; énfasis añadido).

20 "No existen derechos burgueses, sino una comprensión burguesa de los derechos. Entenderlo de este modo permite impugnar el uso doctrinario particular y no los derechos en sí mismos, nacidos de un largo proceso de luchas sociales que los arrancó, en efecto, a las clases dominantes" (Fernández \& Guanche, 2010: p. 6). 


\section{Tiempos de cambios, pero... ¿y la democracia cuándo?}

Para muchos investigadores, entre los que me incluyo, es patente que los cubanos encaran hoy el agotamiento del pacto social postrevolucionario que durante décadas suministró políticas sociales amplias y generosas, a cambio de la máxima lealtad de la población y la cesión de buena parte de sus derechos civiles y políticos al Estado. Por ende, "presenciamos la paulatina clausura del esquema de gobernabilidad sustentado sobre ese pacto, circunstancia que provoca la necesidad concientizada de la población y las elites —en diversas formas, urgencias y sentidos - de modificar el orden vigente" (Chaguaceda \& González, 2013: p. 53). Tal necesidad despierta notables resistencias, incertidumbres y ambigüedades en torno a los modos de acometer el cambio con eficacia y oportunidad.

En este contexto de tensión social, desde 2008 — pero fundamentalmente a partir de 2011 - el gobierno del presidente Raúl Castro ha promovido un lento proceso de reformas, denominado de manera eufemística "actualización del modelo económico cubano", y que ha generado grandes expectativas dentro y fuera de la isla caribeña. Las transformaciones responden en parte a un cúmulo de añejas demandas de los ciudadanos; aunque también a una estrategia de recomposición del bloque hegemónico que intenta oxigenar la deprimida, ineficiente y estatizada economía nacional, sin renunciar un ápice a sus pretensiones totalitarias. Pero algo está claro: las reformas trascienden ampliamente el mero ámbito de la producción y los servicios.

Coincido con Claus Offe (2014), cuando precisamente en una conferencia en Cuba afirmó que "los sistemas económicos no tienen en sí nada de natural", sino que más bien responden a decisiones tomadas por actores concretos, en coyunturas históricas determinadas, ante un abanico amplio de posibilidades. En su consideración, tales alternativas económicas institucionales poseen una naturaleza predominantemente política, debido a tres razones fundamentales: "1) se toman (y son defendidas y criticadas) en términos del interés de sociedades enteras en su bienestar, 2) se basan en una concepción de justicia (por definición controvertida) y, 3) se llevan a cabo por una autoridad politica" (Offe, 2014: p. 4), dotada de una legitimidad específica que la capacita para tomar decisiones vinculantes referidas a la totalidad de la población.

En consonancia con Offe, el economista cubano Pedro Monreal insiste:

La actualización es un proyecto eminentemente político, cuyo leitmotiv central es el remozamiento de un modelo económico estatal centralizado (modelo que no es incompatible con ciertos grados y formas de descentralización), y que es concebido como mecanismo de afianzamiento de un sistema político unipartidista, al cual se subordina todo el diseño económico. [...] la "actualización del modelo 
económico" resulta un episodio marcadamente subordinado a la cuestión política. Es la "cosa" política ("cosa" entendida aquí en su sentido ontológico relativo a la esencia) lo que determina y por tanto subordina a ella el diseńo y la dinámica de la actualización económica, y no al revés. (Monreal, 2015: pp. 3-4).

Por tales razones, este pensador prefiere introducir, dentro del complejo de mutaciones estructurales, la noción de "reforma del Estado", también apropiada para el caso de la nación antillana. Esta herramienta conceptual explica mejor el ambicioso proyecto del gobierno que "procura establecer, en menos de diez años, las bases para la construcción de una nueva gobernanza del país" (Monreal, 2015: pp. 3-4). La estrategia conlleva una reformulación del "poder del Estado", por un lado, y de su "capacidad estatal", por el otro. ${ }^{21}$

En sentido general, puede afirmarse que las reformas son positivas, en tanto combaten el inmovilismo acumulado en los últimos años de gobierno directo y personalísimo de Fidel Castro, favorecen la pluralización de los sujetos socioeconómicos, brindan al mercado un margen (todavía estrecho) frente al plan hipercentralizado, y abren ciertos espacios de oferta/consumo de bienes y servicios muy demandados por la población.

No obstante, las reformas se encuentran entrampadas en una relación asimétrica que otorga ventajas a los actores mercantiles y privilegiados por el régimen político, frente a otros comunitarios y marginados. Acusan un manifiesto sesgo autoritario y tecnocrático que convida a moderar el exceso de entusiasmo, y a esbozar algunos señalamientos a su real desempeño. ${ }^{22} \mathrm{El}$ horizonte de la "actualización" no incluye, hasta ahora, ni el más mínimo guiño a las reglas y

21 En su distinción de estos dos conceptos, Monreal (2015: pp. 6-7) explica que el "poder del Estado" emana de la propia naturaleza del "juego político" que convierte relaciones políticas en relaciones de poder y en estructuras de poder, lo que condiciona la posibilidad de que el Estado pueda asegurar las condiciones para impartir una determinada direccionalidad a la sociedad. Por otra parte, siguiendo el planteamiento de Maximiliano Rey (2014), pudiéramos considerar que: "la capacidad estatal alude a cómo desde la dirección del Estado se puede movilizar el andamiaje político-administrativo, en vinculación con el contexto social de ese determinado sector de políticas, que le permita plasmar las decisiones". Es decir, que la "capacidad estatal" se refiere esencialmente a cómo se desarrollan las actividades en que se traduce el poder previamente definido del Estado.

22 "Evaluada desde la perspectiva del desarrollo, y no solamente desde el ángulo de la macroeconomía, la actualización es igualmente decepcionante. No por el hecho de no poder 'entregar' desarrollo —una meta que ciertamente exige plazos mayores - sino por el escaso efecto que la actualización está teniendo en la creación de condiciones cruciales para impulsar el desarrollo, específicamente en lo relativo a lo que se requeriría hacer para colocar, de manera estable, una parte creciente de la fuerza laboral del país en trayectorias tecnológicas y organizativas ascendentes (transformación orientada hacia una estructura de mayor 'valor agregado'), a la vez que se garantizase que esa fuerza laboral estuviese en capacidad de 'capturar' los beneficios sociales del proceso, incluyendo mayores salarios y mejores condiciones laborales, en la línea del concepto de 'trabajo decente' promovido por la Organización Internacional del Trabajo (огт)" (Monreal, 2015: p. 8). 
prácticas de la democracia. Por eso los críticos del proceso de cambios abogan por la discusión de nuevas leyes entre parlamentarios y ciudadanos —en detrimento de los usuales decretos gubernamentales—, y por un diálogo nacional sobre la añorada democratización que permitiría a los ciudadanos organizarse y actuar con autonomía (Chaguaceda \& González, 2015). En Cuba existe "un pluralismo social que urge ser canalizado en forma de consensos constructivos hacia metas comunes" (Guanche, 2010: p. 5).

Ante un régimen que desprecia y obstruye la apertura del campo político con una añeja receta totalitaria: monopolio legal y fáctico sobre la representación/ participación políticas, sazonado con control/represión del activismo cívico, la única alternativa sostenible a largo plazo apunta a la constitución de un conjunto mínimo de acuerdos y acciones concretas acerca de los modos de restituir los derechos a la ciudadanía y restringir la arbitrariedad de los órganos estatales.

\section{La democracia anhelada}

En completa oposición a la herencia capitalista, a lo largo de la historia la tradición socialista sobreestimó con fuerza los derechos sociales por encima de los individuales, como ya mencionamos; además, priorizó las garantías materiales en detrimento de las libertades jurídicas y formales. Por antonomasia, este esquema estadocéntrico —orientado hacia la justicia social— privilegió la democracia "material" sobre la democracia formal. En el otro extremo "de la cancha”, su contrincante capitalista hizo todo lo contrario. Sin embargo, desde ambos polos, prestigiosos juristas y sociólogos han abogado por la paridad entre los diferentes tipos de derecho, su interdependencia y naturaleza holística. Similar razonamiento puede trasladarse a la democracia, y "hace desaparecer la precedencia de la democracia material sobre la democracia formal, y la considera como una integralidad: la democracia es social y es política, es formal y es sustancial" (Guanche, 2010: p. 5).

Es con ese enfoque complementario que aspiro a una sociedad cubana que incorpore una base institucional para la tolerancia, o sea, la posibilidad estructural de convivencia política entre sistemas de creencias sustantivamente diferentes (inclusive antagónicos), aunque, de manera inevitable, uno de ellos ostente el poder de decisión (Guanche, 2010). En primer lugar, habría que desmantelar de una vez por todas el monopolio autoritario del Partido Comunista (o de cualquier otro que lo intente), desestigmatizar el disenso y favorecer la competencia política legal, en condiciones de igualdad y transparencia, regida por principios operativos democráticos. Sin que esta democratización "formal" signifique el abandono de las garantías sociales vigentes, cuyos contenidos y 
calidad pueden perfeccionarse con el tránsito a un socialismo participativo o autogestionario $^{23}$ (que no anárquico).

El valor instrumental de la democracia para nada contradice su componente teleológico: "Es un fin que se explica con un medio y un medio que se justifica por un fin. Combina ambos extremos. Así, no es sólo la 'máquina' lo que amamos en la democracia, sino aquello que 'hacemos' con la máquina”, sostiene Bilbeny (1999: p. 37), quien está convencido de que la democracia es el mejor medio para un mundo más libre y menos desigual.

Soy consciente de las incertidumbres y pasiones encontradas que generaría semejante decurso en sus primeras etapas. "El desarrollo típico de un proceso de democratización implica también muchas salidas en falso, errores de juicio, rodeos y consecuencias no intencionales" (Whitehead, 2011: p. 49). Sin embargo, la naturaleza abierta, dinámica, inestable, precaria y conflictiva de los procesos de democratización, no debe limitar la adopción e implementación de un núcleo básico de arreglos y procedimientos neutrales que, como bien afirma Whitehead, "anclen" en tierra firme el sueño democrático (en buena medida flotante, errático, conflictivo y hasta un tanto mítico). En definitiva, la democracia "consiste en un progreso hacia un tipo de política más basada en reglas, más consensual y participativa" (Whitehead, 2011: p. 47).

Otro importante pilar de mi propuesta apunta al establecimiento y consolidación de un Estado de derecho ${ }^{24}$ que ampare a los ciudadanos frente al despotismo de funcionarios y empresarios domésticos o foráneos, y que "auspicie los procesos e instituciones de innovación democrática y participación ciudadana capaces de corregir el conocido problema de las democracias delegativas y los poderes fácticos encumbrados dentro del modelo neoliberal" (Chaguaceda $\&$ González, 2013: p. 54). En la senda democratizadora, deviene un imperativo luchar por la implementación de políticas de descentralización, que pongan fin al tutelaje partidista y promuevan una participación ciudadana autónoma y de calidad:

23 En Cuba existe una corriente de pensamiento de izquierda que lleva décadas abogando por un movimiento descentralizador y "desestatizador", por el desarrollo de una economía cooperativa y autogestionaria, y el empoderamiento local, sindical y cívico. Este movimiento intelectual ha sido burdamente ninguneado y, en ocasiones, hasta criminalizado.

24 "El progreso de la democracia tiene lugar, en mi opinión, no sólo mediante la expansión de los derechos fundamentales y de su garantía sino también a través de la extensión del Estado de derecho al mayor número de ámbitos de vida y esferas de poder, con el fin de que también allí sean tutelados y satisfechos los derechos fundamentales de las personas. Son los poderes desregulados que se desarrollan en su interior los principales obstáculos de orden económico y social que limitan de hecho la libertad y la igualdad de los ciudadanos" (Ferrajoli, 2000: pp. 115-116). 
La Participación ciudadana, se transforma en un mecanismo orientado a complementar la democracia formal, a llenar el vacío con nuevos contenidos y para hacer valer derechos de sectores que no encuentran, ni desean espacios de empoderamiento, a través de los vehículos de los partidos políticos. [...] Darle protagonismo a ese sujeto, más allá de la asistencia periódica a ejercicios electorales, es el reto de la institucionalización de la participación ciudadana. (Baltodano, 2004: p. 152).

Semejante tipo de participación requiere cuando menos de una comunidad amplia de ciudadanos conscientes, críticos, activos, responsables y habituados a deliberar con respeto (valores todos escasos en la sociedad cubana actual). Como bien resumiría Whitehead: "La democracia tiene una afinidad electiva, o tal vez incluso una conexión necesaria, con un tipo particular de cognición ('pensamiento reflexivo') y una orientación social particular (un 'ethos de responsabilidad')" (2011: p. 34). Precisamente, debido a esta cualidad crítica de la cognición del ciudadano democrático — continúa el británico-, "en asuntos políticos ni siquiera el consenso de valor más fuerte y el edificio conceptual más robusto pueden llegar a ser por completo inmunes a la duda y la renegociación" (2011: p. 34). Axioma que si los líderes de la Revolución cubana entendieron en un inicio, luego se encargaron de proscribirlo.

En su libro Democratización. Teoría y experiencia, Whitehead echa mano hábilmente del ejemplo de Cuba. De este "caso duro" se vale para defender el potencial democrático de la deliberación ciudadana, como medio de evaluación de alternativas políticas competidoras:

Si los ciudadanos de Cuba, relativamente aislados de sus vecinos, se pusieran a deliberar y sacaran la conclusión de que su forma de gobierno de un solo partido comunista fuera democrática, ¿estaríamos obligados a permitir que esa sentencia anulara juicios y definiciones externas más convencionales? Teóricamente, esto podría ser necesario, en mi opinión, pero sólo si los ciudadanos de Cuba realmente estuvieran en libertad de deliberar (por ejemplo, necesitarían acceso abierto a puntos de vista competidores y sus conclusiones personales decidirían el resultado) e incluso entonces, únicamente habrían llegado a un veredicto provisional. Por lo tanto, la "democracia comunista" resultante dependería permanentemente de la aprobación revocable de sus ciudadanos. A su debido tiempo, dado el supuesto acceso a puntos de vista rivales, tanto Cuba como sus vecinos llegarían a un solo veredicto acerca de si esta variante de democracia sería admisible o no. Esto es así porque con el tiempo la opinión en Cuba se desviaría por exposición al escepticismo externo, o la resistencia externa se debilitaría por la persuasión cubana. En este contexto es útil que la democracia sea un ideal inalcanzable tanto como una etiqueta descriptiva. (Whitehead, 2011: pp. 41-42). 
Como hemos expuesto, y bien presume el autor, la "libertad de deliberar", el "acceso abierto a puntos de vista competidores", la "exposición al escepticismo externo", la provisionalidad y revocabilidad de los veredictos políticos, etc., son meros supuestos que urge concretar en la Cuba actual. Tales falencias deslegitiman el autobombo de la "democracia comunista", que más bien presenta alarmantes suspensos en el procesamiento democrático de los inevitables desacuerdos. En cualquier caso, coincido con Whitehead en que, dada la complejidad, heterogeneidad y larga data de los procesos de democratización, conviene siempre pensar, hablar y medir en términos de calidad de la democracia, antes que usar el engañoso lenguaje de la "consolidación".

Por último, quisiera referirme a la conveniencia de incorporar a la particular experiencia democratizadora cubana, las herramientas de presión, sanción, control, fiscalización y obstrucción, que Pierre Rosanvallon (2007) ha englobado bajo el polémico concepto de la contrademocracia (cuyos contenidos abrazo tanto como rechazo la etiqueta que los engloba ${ }^{25}$ ). Respecto a dichos "poderes correctores", este autor identifica tres modalidades: la vigilancia, la denuncia y la calificación. En contraste con la intermitente asistencia a las urnas (democracia electoral), la eficiencia de estos "contrapoderes" depende de su condición permanente, de su constancia. Rosanvallon rescata un ideal de gobierno de la voluntad general centrado en la facultad de impedir: la democracia negativa, de rechazo o de imputación. Esto es: "la vigilancia del pueblo controlador, perpetuamente activo, como el gran remedio para el mal funcionamiento de las instituciones, en particular para remediar lo que podríamos llamar la entropía representativa (es decir, la degradación de la relación entre elegidos y electores)" (Rosanvallon, 2007: p. 30).

En cuanto al vacío de estos mecanismos de control democrático, la experiencia del socialismo de Estado en no pocos aspectos es peor que la del capitalismo. Al decir del sociólogo cubano Juan Valdés Paz (2009), la consecuencia inmediata y nefasta de la hipercentralización es un burocratismo inmunizado contra cualquier pretensión ciudadana de fiscalización. En la tradición comunista y socialista - afirma- el burocratismo no consiste en un mero supernumerario de burócratas que estorba. "Burocratismo es tomar decisiones sin control de la sociedad sobre ellas. Entonces, cuando hablamos de burocratismo en realidad lo que queremos decir es que hay una insuficiencia democrática porque la sociedad no tiene control sobre las políticas en curso" (Valdés, 2009: p. 63). En la "receta" de la ańorada transición cubana a la democracia no pueden faltar

25 A mi juicio, todas las formas de "contrapoder" explicadas por Rosanvallon pueden y deben acodalar la "bóveda" de la democracia, sin prefijos ni adjetivos pretensiosos. 
estos ingredientes rosanvallonianos, so pena de degenerar en un capitalismo de Estado más atroz que el socialismo postotalitario.

Para concluir, es justo señalar que los aspectos esbozados aquí, en torno a la necesaria democratización que demanda Cuba, no agotan ni mucho menos la problemática bajo análisis. Apenas constituyen gráciles brasas para atizar el debate y consumirse en el fuego lento de la discusión, junto con otros rescoldos de diversas "maderas". Mucho necesitamos los cubanos la institucionalización del debate y, más aún, el vertimiento (carácter vinculante) de los resultados de la deliberación en leyes, políticas públicas y estructuras sociales. La evolución en el complejo ámbito de la cultura, propenso a la inercia y usualmente resistente al cambio, no es menos importante. Aunque "la democracia no sirve para hacer todas las cosas", ni para siempre "hacer las cosas bien o de modo eficaz" (Bilbeny, 1999: p. 21), a mi entender, no cabe duda de que, bajo su perfectible manto, los cubanos disfrutaríamos de una sociedad civil más libre, justa y civilizada, estaríamos más cerca de erguirnos y rozar esas promesas pospuestas por décadas.

\section{Referencias}

Aguirre, B. E. (2002). Social control in Cuba. Latin American Politics and Society, 44(2), 67-98.

Alonso, A. (2015). Una carta de Aurelio Alonso. [Segunda cita, blog de Silvio Rodríguez]. Recuperado el 25 de marzo de 2015, de http://segundacita.blogspot.mx/2015/03/una-carta -de-aurelio-alonso.html

Arendt, H. (1997). ¿Qué es la politica? Barcelona: Paidós.

Azor Hernández, M. (2014). La disputa por el territorio, los espacios y el léxico entre el Estado y la sociedad civil cubana. Revista de Comunicación de la SEECI, 18(35E), 151-158.

Baltodano Marcenaro, M. (2004). Democracia, poder y participación ciudadana. En Serrano Caldera, A. (Ed.). Legalidad, legitimidad y poder en Nicaragua (pp. 133-154). Managua: Fundación Friedrich Ebert/Centro Interuniversitario de Estudios Latinoamericanos y Caribeños.

Bilbeny, N. (1999). Democracia para la diversidad. Barcelona: Ariel.

Chaguaceda, A. \& González, L. de J. (2015). Participación comunitaria y gobiernos locales en Cuba. La experiencia de los Consejos Populares y el impacto de las reformas de Raúl Castro. Espiral. Estudios sobre Estado y Sociedad, (63), 125-152.

Chaguaceda, A. \& Geoffray, M. (2015). Cuba: dimensiones y transformaciones político-institucionales de un modelo en transición. En Bobes, V. C. (Ed.). Cuba: ¿Ajuste o transición? 
Impacto de la reforma en el contexto del restablecimiento de las relaciones con Estados Unidos (pp. 47-86). México: Flacso México.

Chaguaceda, A. \& González, L. de J. (2013). Cuba: la reforma y sus pendientes, Este país. Tendencias y opiniones, (272), 51-55.

Fernández, J. A. \& Guanche, J. C. (2010). Un socialismo de ley. En busca de un diálogo sobre el constitucionalismo socialista cubano en el 2010. Caminos: Revista Cubana de Pensamiento Socioteológico, (57), 1-14.

Ferrajoli, L. (2000). El garantismo y la filosofía del derecho. Bogotá: Universidad del Externado de Colombia.

García Belaunde, D. (2004). El Tribunal de Garantías Constitucionales y Sociales de Cuba (1940-1952). Apéndices. Boletín Mexicano de Derecho Comparado, (109), 283-312.

Guanche, J. C. (2010, 7 de noviembre). Cuba: por un consenso para la democracia. Sin Permiso. Recuperado de http://www.sinpermiso.info/textos/index.php?id=3697

Hobbes, T. (1982). Leviatán. Bogotá: Skla.

Linz J. (2009). Obras escogidas. Vol. 3: Sistemas totalitarios y regímenes autoritarios. Madrid: Centro de Estudios Políticos y Constitucionales.

Locke, J. (1990). Segundo tratado sobre el gobierno civil. Madrid: Alianza Editorial.

Monreal, P. (2015). ¿Actualización del modelo o reforma del Estado? Cuba Posible. Recuperado el 4 de mayo, de http://cubaposible.net/articulos/actualizacion-del-modelo-o-reforma-delestado-2-aa5-3-aa8-4-3

Mouffe, C. (2012). La paradoja democrática. El peligro del consenso en la política contemporánea. Barcelona: Gedisa.

Offe, C. (2014). Socialismo democrático: algunas alternativas para una economía política (Notas para una conferencia en Cuba, enero de 2009). Estudios Sociológicos, 32(94), 3-15.

Quijano, A. (2014). Cuestiones y horizontes: de la dependencia histórico-estructural a la colonialidad/descolonialidad del poder. Buenos Aires: CLACso.

Rey, M. (2014). Capacidad estatal y poder del Estado en Latinoamérica del siglo xxı: Una perspectiva política para el análisis de las políticas públicas y la estatalidad. Estado y Políticas Públicas, (2), 115-139. 
Rojas Gutiérrez, R. (2015). La democracia postergada. Pluralismo civil y autoritarismo político en Cuba. En Bobes, V. C. (Ed.). Cuba: ¿Ajuste o transición? Impacto de la reforma en el contexto del restablecimiento de las relaciones con Estados Unidos (pp. 145-162). México: Flacso México.

Rojas Gutiérrez, R. (1997). Del espíritu al cuerpo de la nación. Identidad y ciudadanía en la cultura política en Cuba. Estudios Sociológicos, 15(43), 239-260.

Rosanvallon, P. (2007). La contrademocracia. La politica en la era de la desconfianza. Buenos Aires: Manantial.

Torres, A. Nieves, J. H., Prieto, D., D’Angelo, O. et al. (2015, 29 de marzo). Institucionalizar la diversidad: hacia una nueva Ley de Asociaciones para Cuba. Cuba Posible. Recuperado el 22 de marzo de 2017, de https://cubaposible.com/cuaderno/institucionalizar-la-diversidadhacia-una-nueva-ley-asociaciones-cuba/

Valdés Paz, J. (2009). El espacio y el límite. Estudios sobre el sistema politico cubano. La Habana: Ruth Casa Editorial/Instituto Cubano de Investigación Cultural Juan Marinello.

Whitehead, L. (2011). Democratización. Teoría y experiencia. México: Fondo de Cultura Económica.

Žižek, S. (2010). En defensa de la intolerancia. Madrid: Diario Público.

Recibido el 12 de mayo de 2015. Aceptado el 17 de diciembre de 2016. 